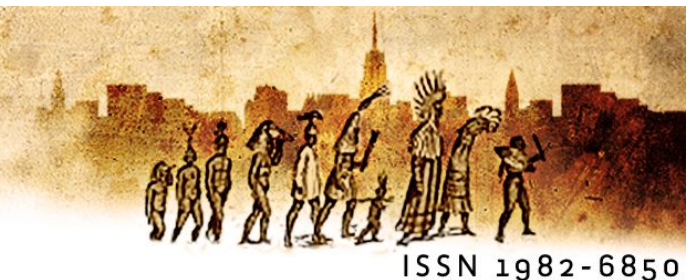

\title{
Realinhamento Identitário do (futuro)professor: efeitos representacionais no e pelo relatório de estágio
}

\author{
Pollyanne Bicalho Ribeiro ' (UFC)
}

Fernanda de Castro Modl ii (UESB)

\begin{abstract}
Resumo: O objetivo deste artigo é discutir sobre o relatório de estágio (JACIARA; LEUROUIN, 2011; LEUROUIN, 2008; LOPES, 2007) como um gênero de texto cujas relações dialógicas indiciam uma análise do agir humano (BRONCKART et al., 1996; BRONCKART, 2006) constitutivo da e para a formação inicial do professor. Daí, no enquadre teórico-metodológico do Interacionismo Sociodiscursivo, elegermos a categoria de análise modalização para via textualidade acessarmos índices do processo discursivo de (re)alinhamento identitário do (futuro)professor. Os dados revelam movimentos em que estagiários de Letras constroem objetos de discurso, ora em torno de si mesmos, um eu-professor, ora em torno do ele-professor, o que registra a indissociabilidade das dimensões verbal e social na interação professor-formador e professor em formação de que o relatório é resultado.
\end{abstract}

Palavras-chave: Relatório de Estágio; Formação Inicial do professor; (Re)alinhamento identitário; Modalização.

\begin{abstract}
This paper discusses about the initial teacher training report (JACIARA; LEUROUIN, 2011; LEUROUIN, 2008; LOPES, 2007) as a text genre as its dialogic relationships indicates an analysis of human action (BRONCKART et al., 1996; BRONCKART, 2006) which initially determines and takes part in the initial teacher formation. Therefore we chose the Socio-discursive Interactionism as theoretical and methodological framework and we use modalization as an evaluation category gaining access to textual signs in discursive process of (future) teacher's identity Footing. The archived data leads to the conclusion that trainee teachers in Letters do construct objects of discourse about themselves as 'a future teacher', or observing 'the other as a teacher', proving an undeniable connection between verbal and social dimensions, which takes places in the interaction of teacher educators and trainee teachers themselves.

Keywords: Initial teacher training report; Initial teacher formation; Identity Footing; Modalization.
\end{abstract}




\section{Introdução}

Profícuos e variados são os estudos acerca do agir humano implicado no trabalho do professor, que têm sido desenvolvidos no interior do quadro teórico-metodológico do Interacionismo Sociodiscursivo. Dentre os princípios de trabalho, estão o de que o agir humano se configura e reconfigura em textos e ainda que a textualidade guarda, em seus diferentes níveis, traços reveladores das ações de linguagem realizadas pelos sujeitos nas situações de trabalho (MATENCIO, 2005;2009; LEURQUIN, 2008; 2011; MACHADO, 2004; 2005; LOPES, 2005; GUIMARÃES, 2005; GUIMARÃES; MACHADO, 2005).

Daí se considerar que as ações e discursos, constitutivas do trabalho do professor, presentificadas em certos gêneros de texto, mereçam ser cada vez mais investigados, porque estudando condutas verbais particulares, (entre)vemos relações dialógicas sustentadoras dessas condutas.

Compreender essas condutas interessa-nos não apenas porque somos professorasformadoras de professores, e, assim, porque lidamos com necessidades de didatização, mas sobretudo porque entendemos que estudar o trabalho do professor implica compreender "como as ações de linguagem em que se engajam [os sujeitos] (re)dimensionam saberes e representações" (MATENCIO, 2009, p. 17).

O trabalho do professor-formador de professores requer, assim, um duplo movimento: didatizar a partir de pesquisas e fazer pesquisas a partir de demandas de didatização (ZANDWAIS, 2012).

Nessa direção, neste artigo, trazemos resultados preliminares de uma parceria interinstitucional de pesquisa na qual analisamos a modalização (BRONCKART, 1999) no gênero de texto relatório de estágio (LEURQUIN, 2008; JACIARA; LEURQUIN, 2011; LOPES, 2007)como uma ação de linguagem que parametriza representações do agir do (futuro)professor, ali materializadas.

Daí defendermos que a preparação em sala de aula para as atividades de docência, enquadradas nos estágios supervisionados, figure um lugar para se acessar, via enunciação, também representações identitárias em curso acerca do profissional professor.

Analisar as modalizações observadas nos relatórios dos estagiários nos pareceu um meio interessante para a compreensão de como os fatos vivenciados pelos 
(futuros)professores no âmbito do estágio são apreendidos, sentidos, interpretados e expressados.

Discussão válida, apostamos, uma vez que o relatório do estágio compõe uma atividade discursiva indexada, crítica, através da qual os estagiários expõem modos de significar a profissão, que irão assumir após a conclusão do curso, na dialogia com o professor supervisor. Nessa seara, as ponderações, que aqui apresentamos, prestam-se a demonstrar que, no relatório de estágio, marcas de subjetividade emergem e nos possibilitam traçar estratégias metodológicas mais contundentes para a promoção de uma formação cada vez mais satisfatória.

A seguir, apresentamos sumariamente o enquadre teórico-metodológico. Na seção seguinte, enfocaremos o gênero relatório com objetivo de dimensionar o modo como tal gênero instancia aos (futuros)professores a possibilidade de narrarem suas mudanças, como são percebidas e o que elas apontam como elementos desencadeadores de processos de formação identitária. Na sequência, resenhamos a modalização como uma ação de linguagem e, chegamos, efetivamente à análise de excertos do corpus. Fechamos o texto buscando ver no diálogo estabelecido e perspectivado com o professor-formador no e pelo relatório, quais são as implicações dos dizeres dos estagiários para representação sobre o trabalho docente no âmbito da formação inicial do professor.

\section{A abordagem teórico-metodológica proposta}

Como corpus de análise, trazemos excertos de relatórios de estágio, que perfazem o banco de dados de uma parceria interinstitucional de pesquisa ${ }^{1}$, em curso, em que temos nos dedicado a experimentar e praticar a análise de dizeres de professores em formação como uma atitude política de intervenção no universo da formação do professor e, assim, extensivamente nos discursos e práticas que esses dizeres fazem movimentar no imaginário do grupo de pertença, mais especificamente das turmas com as quais exercemos a docência em disciplinas de prática de ensino (estágios de observação, regência e didáticas da linguagem) do curso de Letras.

\footnotetext{
${ }^{1}$ Projetos de pesquisa, por nós coordenados e nos quais atuamos co-colaborativamente, através do PID e PIBIC, no âmbito da UFC, Constituição Identitária do Professor de Língua Portuguesa e Palavra na sala de aula: discursos e recursos para a formação docente (UESB - FAPESB).
} 
Os relatórios analisados na pesquisa, dos quais trazemos excertos para análise neste trabalho, são produções requeridas pelas disciplinas relacionadas à prática de ensino Estágio de observação e regência ${ }^{2}$. Nessas disciplinas, os alunos devem observar 10 horasaula (estágio de observação) e no caso do estágio em regência, repete-se a etapa de observação e, em seguida, a assunção do estagiário como regente. As experiências, vivenciadas nesses estágios, devem ser narradas e refletidas através da escrita de um relatório.

Do enlace teórico-metodológico ao Interacionismo Sociodiscursivo (BRONCKART, 1999, 2005, 2006, 2010), nossas pesquisas guardam a filiação de que "contribuindo para a atividade de linguagem, cada ser humano, portanto, participa das avaliações sociais e, nesse quadro, aplica os critérios coletivos de avaliação e julga a pertinência do agir dos outros em relação aos mundos representados" (BRONCKART, 1999, p. 43).

Como as trocas são da ordem do simbólico, "as propriedades específicas do comportamento humano resultam de uma socialização particular que é possibilitada pela emergência histórica de instrumentos semióticos" (BRONCKART et al., 1996, p. 69) do que resulta o fato de que os processos sociais e as estruturas culturais importam ao Interacionismo Sociodiscursivo, porque indiciam o processo de desenvolvimento humano efetivado na linguagem.

Assim, acreditando na centralidade das ações de linguagem nos processos de textualização (MATENCIO, 2005; 2009), escolhemos 6 excertos de relatórios de estagiários de duas universidades públicas do nordeste do Brasil, a fim de acessarmos representações do agir docente e do ensino como trabalho (MACHADO, 2005), a partir de um olhar lançado para a modalização como uma ação de linguagem necessária à gerência dos mecanismos enunciativos para a análise do trabalho docente (GUIMARÃES, 2005), especificamente, do trabalho do professor-formador de professores contribuindo, assim, para a reivindicação da compreensão do gênero relatório de estágio em seus valores social, histórico e educacional (JACIARA; LEURQUIN, 2011).

\footnotetext{
${ }^{2}$ Nos cursos de Letras, licenciatura, dos quais participamos e de que os dados são provenientes, as disciplinas de estágios são oferecidas a partir do $6^{\circ}$ período (UFC) e do $5^{\circ}$ semestre (UESB). Nas duas universidades, o relatório compõe uma das principais avaliações, além de requisito para a integralização dos créditos destinados à disciplina.
} 


\section{O relatório como gênero de texto e instância de representações identitárias do (futuro)professor}

O relatório de estágio como prática de linguagem assume na formação inicial do professor a função de locus das (trans)formações ocorridas ao longo dessa formação (Leurquin, 2013). Como gênero de texto e, portanto, produto estabilizado do comportamento humano fruto de uma socialização particular (BRONCKART et al., 1996), alcança sua estabilização no campo das trocas dialógicas da Universidade, já tendo sido objeto de estudo de pesquisadores como Leurquin (2008), Jaciara; Leurquin (2011), Lopes (2007), no escopo do Sociointeracionismo Discursivo, e no campo da Linguística Aplicada por estudiosos como Silva (2008; 2013).

Antes de atermo-nos às especificidades do gênero relatório de estágio, cumpre atualizar sucintamente reflexões acerca de como a categoria gênero é enquadrada no escopo do ISD.

Se da leitura que Matencio (2009, p. 26) faz de Bronckart (2006), "as condutas especificamente humanas ganham o estatuto de ações significantes em atividades sociais, [daí] tem-se que os eventos de interação são o lócus para a atualização do(s) artefato(s) simbólico(s)", isso ocorre porque "um gênero de discurso é, portanto, o que funda simbolicamente o mundo no qual se processa a atividade dos sujeitos."(FAïTA, 2004, p. 68). Disso decorre a necessidade de para se estudar a textualização de ações de linguagem via gêneros de texto, independentemente do gênero, se considerar que

o gênero adotado para realizar a ação de linguagem deverá ser eficaz em relação ao objetivo visado, deverá ser apropriado aos valores do lugar social implicado e aos papéis que este gera e, enfim, deverá contribuir para promover a "imagem de si" que o agente submete à avaliação social de sua ação.(BRONCKART,1999, p.101).

A citação de Bronckart (1999), ao iluminar essa faceta da 'imagem de si', convida-nos a perceber que a abordagem do ISD incorpora - aos princípios teóricos de Voloshinov/Bakhtin e Vygotsky contidos no fato de que o gênero cumpriria o papel de instaurar e viabilizar a atividade comunicativa e, desta forma, funcionaria como um instrumento social capaz de mediar relações entre interactantes, porque não há disjunção entre pensamento e linguagem- mais propriedades relacionadas à situação de enunciação 
(papéis sociais figurados pelos interlocutores, condições de produção de sentido implicadas no trabalho em curso, elementos vinculados à perspectiva espaço-temporal que marcam a textualização, imagens projetadas e finalidades discursivas da instância de regulação da ação). Por essa razão a noção de gênero no quadro do ISD tem suas especificidades.

A natureza ambivalente do gênero o faz ser um importante recurso no que tange a transparecer características peculiares a determinada esfera social, como também movimentos de rupturas, mudanças de paradigmas, (trans)formações ocorridas no interior da esfera social focada. Por isso, analisar o gênero relatório implica reconhecer propriedades do grupo docente, ou seja, ao se investigarem o referido gênero, examina-se, sob certo ângulo, a identidade docente sob a ótica dos estagiários.

Entretanto, conforme bem ressaltam Jaciara \&Leurquin (2011, p. 27) há "uma falta de compreensão do valor social, histórico e educacional que o relatório possui nesse momento tão particular, que é o momento de formação inicial do professor, o momento do seu estágio docente", daí a necessidade de pesquisas que busquem desobvializar o tratamento mecanicista e automático com o gênero, dada a necessidade de se compreender que se gêneros são verdadeiros "modelos que viabilizam a comunicação" (KLEIMAN, 2007, p. 12), cumpre-nos perguntar: que tipo de comunicação/interlocução professor-formador e professor em formação é requerida no gênero relatório? Nossa aposta é de que avançaremos na resposta a essa pergunta olhando para o uso da modalização a partir de uma análise de seus efeitos para a mostra do letramento profissional.

Diante disso, defendemos o olhar investigativo sobre o gênero relatório, somando nossa voz a de outros pesquisadores, a fim de compreendermos a discursivização da prática educativa, já que modos de dizer o agir docente são reveladores de representações concernentes às escolhas metodológicas, à identidade professoral, à interação professoraluno, questões essas tão caras a nós, formadores de professores.

Quanto às características do gênero relatório, Silva (2013, p. 175) salienta o fato de se tratar de um texto acadêmico que, diferentemente de outros gêneros, se abre para "uma escrita marcadamente subjetiva no espaço acadêmico", isso porque talvez se queira "reduzir a probabilidade do aluno-mestre se esconder entre as inúmeras vozes legitimadas na esfera acadêmica, reproduzindo alguns discursos despercebidos ou que não sejam, necessariamente, por ele aceitos ou, até mesmo, produzidos". (SILVA, 2013, p. 175). 
No interior das disciplinas de Estágio supervisionado, temos o relatório de estágio que:

Por meio da ação desse gênero [relatório] é possível refletir em duas dimensões: o fazer do professor (as condições que cercam o seu agir, as habilidades que demonstra ter sobre as atividades de elaboração, planejamento e execução) e as representações que os alunos-estagiários, professores em formação, possuem das ações dos docentes em sala de aula. (LOPES, 2007, p. 222).

Ao olhar para a nossa prática - e, consequentemente, para as representações do gênero que temos construído na dialogia com nossos alunos - cabe reivindicar um pensar (bi)localmente sobre o gênero em nossa pesquisa interinstitucional em que se dê realce à modalização. Isso dada a nossa compreensão de que o gênero relatório não só instancia, mas coopera para ações metacognitivas sem as quais não seria possível a mudança de status do professor em formação. Desse modo, ele se apresenta como um importante meio de acesso às ações, concepções, representações em torno do processo de ensino e aprendizagem e para a alteração identitária do estagiário em um professor licenciado.

$\mathrm{Na}$ e para a gerência da estrutura composicional do gênero relatório, portanto,acreditamos, ser necessário que o professor formador viabilize o enfrentamento, a avaliação e a ressignificação de conflitos experenciados na escola campo de estágio, de modo a orientar os estagiários a expor pontos de vista que materializem contradições, tomadas de posicionamentos da ordem do indivíduo, como também da ordem da coletividade.Ou seja, a desnaturalização do olhar lançado para a cultura escolar marcada na e pela interação didática e na convivência intersubjetiva do estagiário (professor em formação) com os alunos de uma dada turma precisa ser disparada pelo professor formador supervisor do estágio.

Isso porque a formação do professor requer não apenas a revisão e (re)constituição de concepções reveladoras de processos relacionados à construção do conhecimento nos/dos quadros teóricos e metodológicos de referência do Curso de licenciatura, mas também a revisitação de aspectos relacionados ao campo ideológico para a compreensão da sala de aula como lugar genuíno do trabalho do professor, o que requer um deslocamento da vivência na escola básica: do que se vivenciou na condição de aluno para um estar na sala de aula, agora, como professor. Mudança que precisa ser externalizada na e pela linguagem. 
Através do relatório, instaura-se um espaço de confluência entre conhecimentos mais consolidados, mais reiterados e relativamente mais estáveis sobre determinados objetos do mundo docente. Igualmente, demonstram-se conhecimentos recentes, não tão consagrados, sobre esse mesmo mundo.

Daí poder afirmar que, dada a natureza do gênero relatório, é possível verificar (re)constituições identitárias de determinados grupos sociais face aos movimentos de filiações de seus membros. Destaca-se que as referidas filiações corroboram para o delineamento da imagem do sujeito que enuncia, como também do grupo de pertença e, ainda, levam em conta a constituição dos papéis sociais de formando e formador.

É, portanto, nessa direção, que temos trabalhado com o relatório de estágio para

Nessa medida, organizar atividades e propor procedimentos pelos quais os professores em formação possam, efetivamente se socializar nas práticas formativas e naquelas que passarão a atuar, parece ser o caminho mais seguro para garantir que, nesse processo de letramento no âmbito profissional, (...)os sujeitos possam dar continuidade à construção de sua capacidade linguístico-discursiva de forma a agir assumindo posicionamentos identitários que o conduzam à tão almejada autonomia em suas ações de linguagem. (MATENCIO, 2009, p. 26).

Segundo Morin (1996, p. 54), "quando falo, ao mesmo tempo que eu, falamos 'nós'; nós, a comunidade cálida da qual somos parte. Mas não há somente o 'nós'; no 'eu falo' também está o 'se fala'. Fala-se, algo anônimo, algo que é a coletividade fria.". Desse modo, o sujeito nas interações depara-se com a sua "realidade", com a do seu grupo e a da coletividade de um modo geral, gerencia vozes (a sua, a do grupo, a dos outros) e, inevitavelmente, com as marcas ou sob a égide da alteridade, ele modifica a si e ao meio.

O sujeito, então, objetiva às representações sociais, tornando conhecimentos, imagens e crenças, construídas coletivamente, familiares à medida que expressa e se depara com sua singularidade na atividade interacional. Ele opera com a objetivação através da expressão da subjetivação materializada em posicionamentos, atitudes, juízos de valor e, assim sendo, se expõe e ao mesmo tempo expõe a realidade simbolicamente representada.

Holland et al (1998, p. 40, tradução nossa) elucidam o seu entendimento quanto à subjetivação e à objetivação e os efeitos que tais operações trazem para o comportamento dos sujeitos sociais nas múltiplas práticas por eles experienciadas. Traz assim o texto: 
Há, em cada instância, uma microgênese, um microdesenvolvimento de como a pessoa sai do pessoal, senso subjetivo para objetivação, respondendo e delineando-se pela experiência passada como também pelos expedientes e demandas da situação particular. O comportamento essencial - quer em uma expressão de fome, uma solução de um problema, uma construção de uma casa, ou um trabalho de arte - é um produto da pessoa na prática. Esse produto, por sua vez, pode se tornar um símbolo ou representação importante na mediação do futuro comportamento.

Conforme Kleiman (2005, p. 208), as representações sociais "seriam inferíveis pelas operações discursivas mobilizadas, que identificam o enunciador como membro de um determinado grupo, mas também o distinguem de outros membros, mostrando as diferenças" e, diante disso, evidencia-se a "heterogeneidade nas representações de um mesmo grupo.".

Portanto, é interessante notar que o estágio possibilita um enfrentamento do sujeito em relação a como ele se vê e como ele vê ao outro como professor e, assim sendo, tal percepção pode provocar mudanças no modo de se posicionar na prática educativa.

Filiamo-nos, por isso também, à compreensão de Leurquin (2008, p.57) que afirma que o relatório "é uma possibilidade de comunicação, um viés que nos possibilita desvendar práticas docentes, um instrumento de avaliação. Por reunir essas qualidades, ele nos permite contribuir para a política de formação de professores da língua materna".

No contexto da escritura do relatório, queremos flagrar deslocamentos de práticas educativas socioculturalmente valorizadas e, desta maneira, o advento de novas formas de lidar com o objeto ensino/aprendizagem. Há um fluxo de exposições de sentimentos, apontamentos sobre a prática docente e/ou a prática formativa que permite ter acesso ao acervo de representações sociais em torno do ser e do fazer docente que subsidia a qualificação do sujeito docente, do seu grupo e do modo como ele significa o seu trabalho.

As justificativas tematizadas, conforme veremos adiante na análise dos dados, são explicitadas de maneira mais objetivada ou mais próxima e informal em relação ao interlocutor. O interlocutor/professor regente da disciplina de estágio, é compreendido, muitas vezes, como cúmplice ou, no mínimo, confidente das experiências daquele que enuncia. Mas ele não deixa de ser representante da instituição de ensino e, por assim ser, a todo o momento, é visto/compreendido como avaliador no contexto da prática formativa.

No processo discursivo decorrente da produção do relatório, os (futuros) professores ora assumem a condição de objetos de discurso, ao centrar a fala em torno de si, seus 
sentimentos, expectativas, frustrações; ora tais objetos são construídos em torno do eleprofessor, promovendo um distanciamento do locutor.

Reitera-se esse ponto de vista com o excerto proposto por Bronckart (2006) no qual se defende que "todo discurso interior, todo pensamento ou toda consciência apresenta [...] um caráter social, semiótico e dialógico",desse modo, o sujeito é fruto das relações com o outro, das formas de lidar e de significar objetos de discurso e, por sua vez, do uso dos gêneros do discurso tendo em vista a demanda de um dado campo da atividade humana.

\section{A modalização como uma ação de linguagem e seus efeitos no relatório de estágio}

Antes de resenharmos sobre a modalização como um fenômeno linguístico, salientamos que há implicações no modo como olhamos para o conceito como uma ação de linguagem, ao elegermos a modalização como categoria de análise para lidarmos com a textualidade de dizeres de estagiários no enquadre teórico do ISD.

Leurquin e Peixoto (2011, p. 86) dimensionam que, no escopo do InteracionismoSociodiscursivo, "o termo agir diz respeito às diferentes intervenções dos seres humanos, enquanto os conceitos de atividade e ação designam interpretações desse agir".

Na mesma posição de Leurquin e Peixoto (2011), vemos, portanto, o enlace das dimensões social e verbal do agir no quadro do ISD. Assim, o agir humano ir à universidade, compreendido como uma busca de profissionalização, só é possível porque o sujeito é um ator que se assume e, assim, se coloca actante de sua própria história formativa a partir de uma agenda de capacidades, motivações e intenções.

Daí, então, escolhermos a modalização como um modo de acessar esquemas de uso no relatório de estágio, tomado como um instrumento simbólico (SCHNEUWLY, 2002),e, ainda, olharmos para as formas de relatar o circunstanciado na escola campo de estágio, a partir da esquematização de tais ações. Tudo isso, na atividade de interaçãocom o professor formador presentificada no texto relatório. (MATENCIO, 2009).

A modalização é, portanto, para nós uma ação de linguagem, porque aí está pressuposta a nossa interpretação acerca de um agir de linguagem dos estagiários (LEUROUIN e PEIXOTO, 2011) textualizado no gênero de texto relatório de estágio. 
Os olhares linguísticos já lançados em diferentes estudos sobre a modalização são diversos e em muitos autores mantém em comum uma preocupação sobre o lugar do sujeito na linguagem ou sobre como o homem age valendo-se da língua (NEVES, 2006).

No estudo pioneiro da modalidade por Bally (1950, p. 216) no âmbito linguístico, já que a modalidade foi também uma preocupação de lógicos, desde Aristóteles, lemos que "a função lógica da modalidade é exprimir a reação do sujeito pensante a uma representação" em Meyer (1980) como um processo de adesão de um locutor a um enunciado.

Essas concepções permanecemna textualização da definição de modalização em estudos muito recentes, como em Koch (2000, p.32), para quem a modalização, por demonstrar a atitude do falante perante o enunciado produzido, faz parte da atividade ilocucionária, visto que "os operadores argumentativos, as marcas de intenções, as pressuposições e os modalizadores, revelam a atitude do falante perante o enunciado que produz" ou a de Nascimento (2010, p.37), segundo quem a modalização "explica como o locutor deixa registrado, no seu discurso, marcas de sua subjetividade através de elementos linguísticos e, portanto, imprime o modo como esse discurso deve ser lido".

Neste trabalho, orientamo-nos pela tipologia das modalizações de Bronckart (1999), uma dentre as várias disponíveis, que ao analisar as contribuições das classificações surgidas desde a Antiguidade Grega, propõe quatro tipos de funções modalizadoras: as lógicas, as deônticas, as apreciativas e as pragmáticas.

Isso certamente registra um esforço de se procurar demonstrar que existem diferenças conceituais e terminológicas em um ou outro tipo de modalização que pode informar sobre nuances da intenção daquele que diz/escreve.

Desse modo, registramos que a noção de sujeito com a qual operamos é aquela que não prevê um sujeito assujeitado nem tampouco um sujeito intencional, mas um sujeito que está se fazendo ator (LEUROUIN; PEIXOTO, 2011), que está trabalhando discursivamente e, assim, apre(e)ndendo a representar em textos sua própria história de formação profissional.

O trabalho desse sujeito actante pode provocar efeitos que não são previstos por ele mesmo,aquele que enuncia. O que estamos dizendo é que nossa análise não pode nem se basear naquilo que se poderia prever como conhecimentos e intenções dos sujeitos, nem naquilo que se mostra estritamente linguístico e previsto por teorias semânticas.Assim, estamos admitindo que o agir não se constitui só de uma dimensão verbal, formas de se 
organizar elementos linguísticos, mas também da dimensão social, já que é fundado nas interações sociais.

Daí partirmos da tipologia de Bronckart para buscarmos perceber como o uso de modalizações pode ser revelador da assunção de papéis sociais efetuado pelos interlocutores na estrutura organizacional de uma determinada prática social. Elas podem fazer emergir representações interiorizadas dos sujeitos envolvidos com relação à situação de linguagem instanciada por um lugar social específico e, por assim ser, tornar tangíveis caracteres peculiares a essa determinada prática. Diante desse quadro simbólico apresentado, haverá ações e reações, instaura-se um processo avaliativo de escolhas linguísticas, visando encenar discursivamente os papéis atribuídos na interação.

Vertemos, para fins de esquematização, a tipologia de Bronckart (1999) em um quadro que sumariza a proposta do estudioso.

Quadro 1 - Tipologia das modalizações a partir de Bronckart (1999, p. 330-332)

\begin{tabular}{|c|c|c|}
\hline Nome & Características & Exemplos de marcas no uso da língua \\
\hline $\begin{array}{l}\text { MODALIZAÇÕES } \\
\text { LOGICAS }\end{array}$ & $\begin{array}{l}\text { A (Avaliação) de CT (Conteúdos Temáticos) na forma de FA (Fatos } \\
\text { Atestados), FP (Fatos Possíveis) e FPr (Fatos Prováveis) a partir de } \\
\text { critérios do mundo objetivo }\end{array}$ & $\begin{array}{l}\text { Advérbios } \\
\text { (talvez, necessariamente) } \\
\text { Verbos no futuro do pretérito } \\
\text { (saberia, poderia) } \\
\text { Estruturas oracionais } \\
\text { (é evidente que) }\end{array}$ \\
\hline $\begin{array}{l}\text { MODALIZAÇÕES } \\
\text { DEÔNTICAS }\end{array}$ & $\begin{array}{l}\text { A (Avaliação) de CT (Conteúdos Temáticos) na forma } \\
\text { deelementos relacionados ao domínio do direito, da obrigação } \\
\text { social e/ou da conformidade com as normas em uso, apoiada em } \\
\text { valores, opiniões e regras constitutivas do mundo social. }\end{array}$ & $\begin{array}{l}\text { Verbos no presente } \\
\text { (deve, não deve, posso, não posso) } \\
\text { Estruturas oracionais } \\
\text { (É lamentável que) }\end{array}$ \\
\hline $\begin{array}{l}\text { MODALIZAÇÕES } \\
\text { APRECIATIVAS }\end{array}$ & $\begin{array}{l}\text { A (Avaliação) de CT (Conteúdos Temáticos) do ponto de vista da } \\
\text { entidade avaliadora, procedente do mundo subjetivo da voz que é } \\
\text { a fonte desse julgamento, apresentando-os como benéficos, } \\
\text { infelizes, estranhos, etc., }\end{array}$ & $\begin{array}{l}\text { Advérbios } \\
\text { (felizmente, infelizmente), } \\
\text { Expressões de interjeição } \\
\text { (ai de mim!) }\end{array}$ \\
\hline $\begin{array}{l}\text { MODALIZAÇÕES } \\
\text { PRAGMÁTICASS }\end{array}$ & $\begin{array}{l}\text { A (Avaliação) de alguns aspectos da responsabilidade de uma } \\
\text { entidade CT (Conteúdos Temáticos) (personagem, grupo, } \\
\text { instituição, etc.) em relação às ações de que é o agente, e } \\
\text { atribuem a esse agente intenções, razões (causas, restrições, etc.), } \\
\text { ou, ainda, capacidade de ação (poder-fazer, querer-fazer, dever- } \\
\text { fazer). }\end{array}$ & $\begin{array}{l}\text { Verbos no pretérito } \\
\text { (quis, pode, pretendeu, pudesse, devia, } \\
\text { não devia) }\end{array}$ \\
\hline
\end{tabular}

Procedamos, com base nas discussões até aqui empreendidas, à análise dos excertos retirados dos relatórios.Começamos pela apresentação de excertos advindos do estágio de observação, para depois, centrarmos a atenção nos excertos do estágio de regência. 
Os seis excertos, portanto, escolhidos e que passamos a analisar, materializam exatamente o que se mostra mais recorrente no corpus da pesquisa ${ }^{3}$ em termos do uso das modalizações e de seus efeitos.

Ora, realizamos escolhas lexicais para o preenchimento das exemplificações acerca dos tipos de modalização na perspectiva de Bronckart (1999), ou seja, agenciamos opções de análise dos excertos. A leitura por si só dos excertos já indicia muitos elementos passíveis de enquadramento. Portanto, reconhecemos que a análise tabulada, a seguir, representa apenas uma tentativa de buscar na produtividade da tipologia meios para aplicá-la, lidando de forma associada com as apostas de efeitos de sentido provocadas pelo uso das modalizações nos movimentos enunciativos nos quais os estagiários constroem objetos de discurso, ora em torno do outro, o professor observado, no campo de estágio (excertos 1, 2 e 3), ora de si mesmos (excertos 4, 5 e 6) nos relatórios de regência.

Excerto 1 - relatório de observação

$1 \mathrm{O}$ ensino dos gêneros textuais é abordado de forma bastante superficial, pois os professores não levam os alunos à 2reflexão da sua realidade em que vivem tampouco são ensinados sobre o propósito comunicativo dos gêneros e a zimportância destes. Os professores devem repensar sobre a função social do gênero em sala de aula e estimular 4práticas mais condizentes com a realidade dos alunos.

Excerto 2 - relatório de observação

1 Vale salientar que este [o professor] estimula exercícios mecanicistas, de repetição da atividade em casa, de modo 2que os alunos não olhem as respostas corretas e através da repetição da atividade, o conteúdo, automaticamente, 3seria aprendido por estes. Ora, o professor não deve trabalhar com textos descontextualizados, ele deve pensar em 4estratégias que abordem a linguagem em uso e despertem o interesse dos alunos em sala de aula.

\section{Excerto 3 - relatório de observação}

1 Creio que estiveram ausentes durante o período do estágio atividades que trabalhassem com a linguagem de modo

2 mais profícuo e revestido de sentido. Teria sido tão bom se no transcurso das aulas tivesse sido desenvolvido zatividades de seminários - no entanto, seminários que reprovassem a metodologia de um aluno que se posta à frente 4 da turma como mero ledor/decorador de textos previamente instituídos -; de júris simulados; de exposições orais 5 acerca de um conteúdo - precedidas de uma produção escrita -; de debates regrados acerca de temas pertinentes a 6atualidade; enfim, de situações que propiciassem a iniciação e/ou aperfeiçoamento dos alunos em contextos que 7exigem a formulação de posições críticas e argumentativas. Sinceramente, nada vi que ao menos se assemelhasse a 8este modelo de ensino. Notadamente pelo fato de que a dificuldade principal destas situações de produção seja o "ter 90 que dizer" - ou, neste caso, a ausência disto - é que se fundamenta a inexistência destas práticas; pois só se fala e/ou 1oescreve bem quando se tem um repertório de informações significativas; quando se tem um mínimo de conhecimento 11 acerca do exposto. Muito por este obstáculo, ao qual outros se agregam, é que nada pude relatar de procedimentos 12 mudancistas, de ensino reflexivo que seja significativo para a vida dos alunos.

\section{MODALIZAÇÃO DEÔNTICA}

Com o uso da modalização deôntica, aqui, os estagiário se apresentam como sujeitos conhecedores da regulação e daí se sentirem aptos a avaliar a prática do outro (discurso coercitivo). Tais pistas indiciam ao professor-formador modos de interpretar os quadros teóricos e metodológicos referenciados na formação inicial.

\section{Ocorrências}

\section{Excerto 1}

os professores não levam os alunos à reflexão da sua realidade (linhas 1-2)

\footnotetext{
${ }_{3}^{3}$ Para a generalização e escolha dos excertos para esta análise, analisamos 68 relatórios, sendo advindas desse total,40 da UFC (2orelatórios de observação e 20 de regência, fruto do trabalho nos semestres 2014.1e 2015.1) e 28 da UESB (14 de observação e 14 de regência fruto do trabalho nos semestres 2014.1 e 2014.2).
} 
Os professores devem repensar sobre a função social do gênero em sala de aula (linhas 3-4)

\section{Excerto 2}

$\underline{V}$ ale salientar que este [o professor] estimula exercícios mecanicistas (linha 1)

Ora, o professor não deve trabalhar com textos descontextualizados (linha 3)

Ele deve pensar em estratégias que abordem a linguagem em uso (linhas 3-4)

Excerto 3

É lamentável que estiveram ausentes durante o período do estágio atividades que trabalhassem com a linguagem de modo mais profícuo e revestido de sentido (linhas 1-2)

\section{MODALIZAÇÃO APRECIATIVA}

O que é expressado é particularizado pelo sujeito na condição de membro, ora na função do papel acadêmico, ora na função do papel docente. O estagiário evoca quadros teóricos e metodológicos, constituídos e referenciados em sua formação inicial, para justificar a avaliação da prática do professor por ele observada. O professor-supervisor é visto como par, como se compartilhasse das posições, por isso, não é necessário explicitar teoricamente o que está sendo discursivizado.

\section{Ocorrências}

Excerto 1

O ensino dos gêneros textuais é abordado de forma bastante superficial (linha 1)

Tampouco são ensinados sobre o propósito comunicativo dos gêneros e a importância destes (linhas 2-3)

Os professores devem estimular práticas mais condizentes práticas com a realidade dos alunos (linhas 3-4)

\section{Excerto 2}

de modo que os alunos não olhem as respostas corretas e através da repetição da atividade, o conteúdo, automaticamente, seria aprendido por estes (linhas 1-3)

\section{Excerto 3}

que trabalhassem com a linguagem de modo mais profícuo e revestido de sentido.(linhas 1-2)

seminários que reprovassem a metodologia de um aluno que se posta à frente da turma como mero ledor/decorador de textos previamente instituídos (linha 4)

nada vi que ao menos se assemelhasse a este modelo de ensino (linhas 7-8)

\section{MODALIZAÇÃO LÓGICA}

O que ele escolhe tematizar é o que poderia ter sido, tendo em vista o quadro teórico-metodológico de referência. $O$ estagiário, ao mostrar o que não foi feito, indica, sugere o que poderia ter sido, ancorado no quadro de referência. Tal uso indica para o professor-formador uma ação argumentativa do estagiário de preservação da sua face, valendo-se de uma escolha de critica atenuada sobre a prática do outro.

\section{Ocorrências}

\section{Excerto 3}

Teria sido tão bom se no transcurso das aulas tivesse sido desenvolvido atividades de seminários (linha 2)

Notadamente pelo fato de que a dificuldade principal destas situações de produção seja o "tero que dizer" (linha 8)

\section{MODALIZAÇÃO PRAGMÁTICA}

O que ele revela é a constatação da não ocorrência de ações previstas do quadro teórico-metodológico produzido e referenciado na formação inicial. O estagiário atesta sobre o (não) querer do professor observado a partir da expectativa de outra prática. Ao professor-supervisor, o estagiário informa com essa modalização uma espécie de postura fiscalizadora em que ele verifica a aplicação do quadro de referência, sem tecer reflexões sobre as variáveis que concorreram para isso.

\section{Ocorrências}

\section{Excerto 3}

Sinceramente, nada vi que ao menos se assemelhasse a este modelo de ensino. (linha 7)

Nada pude relatar de procedimentos mudancistas, de ensino reflexivo que seja significativo para a vida dos alunos. (linhas 11-12)

Nos excertos 1, 2 e 3, vimos que o estagiário em sua tarefa de observar a prática do outro (o professor em exercício) no campo de estágio, constrói o outro e as ações desse como objetos de discurso.

Com as modalizações deônticas nos três excertos - as mais recorrentemente usadas pelos estagiários no corpus da pesquisa relatórios de observação, com uma recorrência representativa de $69,3 \%$ nas preferências de uso - vimos que o estagiário, de certo modo, registra para seu professor-supervisor do estágio que saberia orientar o agir do professor 
observado, e, na mesma ação linguageira, acaba por se comprometer com esse agir observado, porque deixa pressuposto que, estando no lugar do outro, faria/agiria diferentemente.

Dito de outra forma, o estagiário evidencia não só a sua crença de que outro posicionamento deveria ter sido o tomado pelo professor observado, mas, na condição de membro, ele se engaja nesse posicionamento, referenciando o professor observado, como um outro, um diferente de mim.

Assim, no relatório de observação, o efeito de sentido provocado pelo uso desse tipo de modalização evidencia a imprescindibilidade, sob o julgamento dos locutores, das ações a serem empreendidas no contexto escolar para que esse contexto se aprimore, melhore. $\mathrm{E}$ talvez seja exatamente a natureza da relação de interação didática projetada na escrita pelo estagiário com o seu professor formador que explique a recorrência expressiva da modalização no corpus, ilustrado pelos três excertos analisados.

De certo modo, essa recorrência nos faz refletir sobre uma postura prescritiva. Isto é, o estagiário se coloca como aquele que julga o professor e repreende as decisões metodológicas empreendidas pelo professor observado. Há uma pretensa ideia de que ele, o estagiário, sabe exatamente o que deveria ser feito pelo professor, caso estivesse em seu lugar. Tal constatação vai ressaltar que é possível perceber no dizer dos estagiários, ainda que de maneira implícita, uma reafirmação de poder sobre aquele professor observado. Dessa forma, as modalizações são reveladoras de disputas de poder entre atores sociais, no caso analisado, entre o estagiário, o professor observado e o professor coordenador da disciplina de prática.

O estagiário, baseado nos valores e nas crenças do mundo social em que se encontra inserido, mobiliza suas representações particulares acerca das regras configurativas desse mundo, no caso, o que deveria ser o professor, o que deveria ser objeto de ensino e o que deveria ser aprendido, como atestam os excertos 1, 2 e 3. Assim, é possível não só notar no efeito da modalização deôntica, (os professores não levam, os professores devem, o professor não deve, é lamentável que estiveram ausentes), mas também em uma série de modalizações apreciativas (bastante, mais condizentes, o conteúdo automaticamente seria), a discordância do estagiário com a prática de ensino observada. A maneira enfática com que o estagiário, por exemplo, no excerto 3,questiona o ensino da oralidade na sala de aula é regada por predicações que colaboram para o projeto comunicativo de se colocar 
veementemente contrário às escolhas metodológicas do professor observado. A imagem que se quer construir do estagiário é de se colocar em oposição à imagem do professor observado.

Talvez isso se deva ao fato de que estejam aí acionados pré-construídos como o de que há muito a ser mudado na escola do que decorreria a necessidade de o estagiário se atentar apenas a isso no agir do outro e na base de uma pretensa prescrição se estar mostrando avanços de apreensões teórico-conceituais no interior dos quadros teóricometodológicos de referência do curso e referenciados com e pelo professor supervisor do estágio.

Ademais nos excertos, por meio das modalizações pragmáticas (o $2^{\circ}$ uso mais recorrente no corpus $22,4 \%$ ) e a lógica (10\%), exprime-se a opinião do locutor acerca do que realmente faltou para a prática das aulas observadas. Essa postura assertiva, eivada de valor de verdade, compõe o cenário desejado de que o que o estagiário diz deve ser considerado, relevado, o enunciado ganha carga argumentativa.

Antes da leitura dos próximos excertos e de nossa categorização. Chamamos a atenção para os efeitos de sentidos muito diferenciados decorrentes do uso de cada modalização, quando se trata do relatório de regência. Ou seja, de uma construção de objeto de discurso em torno do que o estagiário fez no campo de estágio e extensivamente de sua vivência como regente.

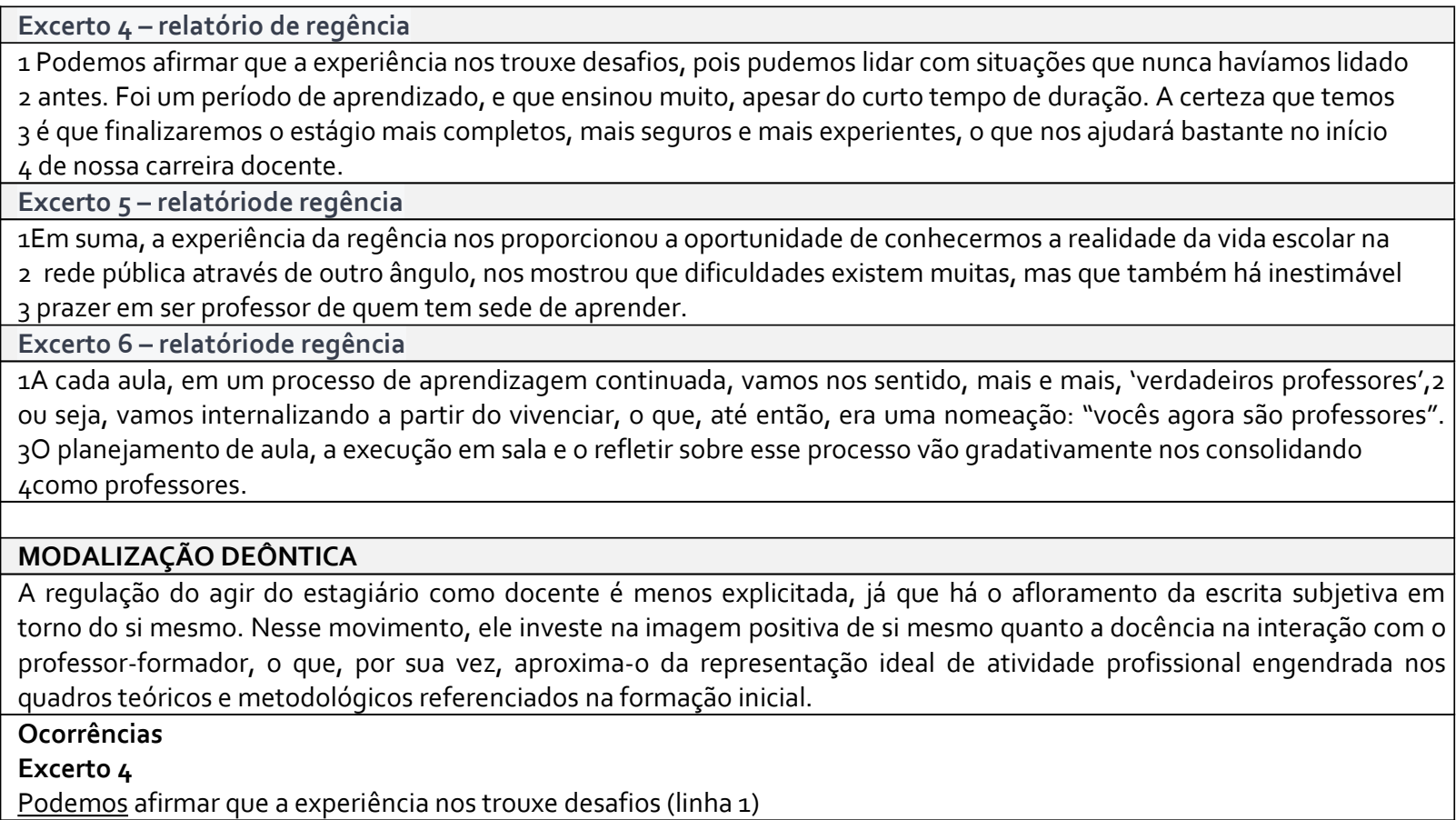




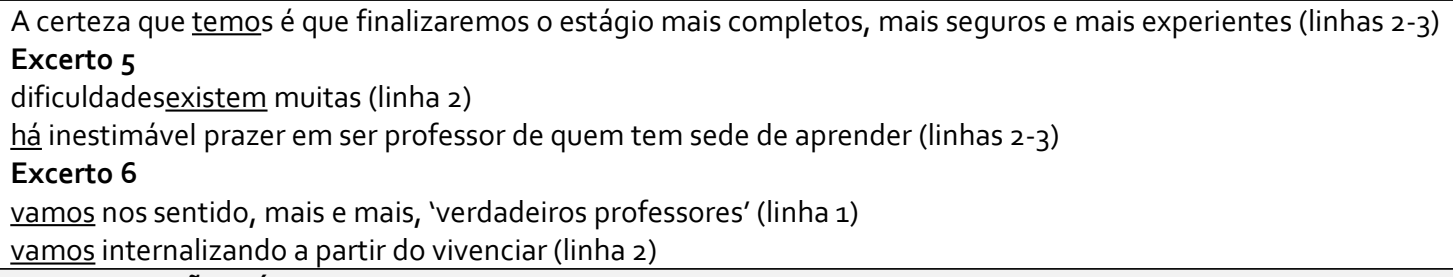

O uso dessa modalização é mais assertivo, já que são os advérbios (e não mais verbos no futuro do pretérito, como no estágio de observação) que orientam para uma interpretação positiva do próprio agir. Apenas sentimentos sobre a experiência são expressos na argumentação, o que ocorre sem trazer exemplos que poderiam colaborar para o projeto argumentativo de que estão preparados para o futuro profissional (fatos prováveis). Isso acaba colaborando para uma imagem do trabalho docente, na interação com o professor-formador, mais próxima do senso comum, afastando-se, pois, do quadro teórico-metodológico de referência tematizado na formação inicial.

\section{Ocorrências}

Excerto 4

A certeza que temos é que finalizaremos o estágio mais completos, $\underline{\text { mais }}$ seguros e mais experientes (linhas 2-3)

Excerto 6

vamos nos sentido, mais e mais, 'verdadeiros professores' (linha 1)

a execução em sala e o refletir sobre esse processo vão gradativamente nos consolidando como professores (linhas 4-5)

\section{MODALIZAÇÃO PRAGMÁTICA}

O que o estagiário revela com o uso dessa modalização é uma espécie de autochancela do seu ser professor certificada pela experiência na regência. Mais uma vez, o quadro teórico-metodológico não é tematizado, aproxima-se mais do discurso do senso comum, o que fragiliza a sua argumentação. Ao professor-supervisor, o estagiário busca atestar que a regência o credenciou para o exercício da docência, ele já se sente efetivamente um professor. A avaliação de si é taxativamente positiva.

\section{Ocorrências}

Excerto 4

Pois pudemos lidar com situações que nunca havíamos lidado antes (linhas 1-2)

Excerto 5

a experiência da regência nos proporcionou a oportunidade de conhecermos a realidade da vida escolar (linha 1)

No estágio de regência, o aluno-estagiário assume o lugar do professor, a primeira pessoa do plural reforça a imagem de pertencimento e colabora para um projeto argumentativo bem diferente daquele produzido no estágio de observação. O uso de todas as modalizações se suaviza, quando há um eu como objeto de discurso.

Outro ponto que nos chama atenção nas textualizações diz respeito à imbricação de papéis sociais (licenciando e professor), traços intercambiáveis que são revelados nos dizeres dos estagiários. Ao mesmo tempo que é aluno da universidade, é também professor.

Nota-se que, na condição de espectador, o estagiário tinha uma representação, sendo que, diante da regência, ele narra, na condição de vir a ser professor, a satisfação da docência.O olhar denunciante de antes, figurado na modalização deôntica, do que faltava na ação do outro, não existe mais. Os estagiários se afastam dos quadros-teóricos de referência na formação inicial para se abrirem para uma escrita ainda mais subjetiva. Não encontramos mais marcas da modalização apreciativa, como não são evocados quadros teóricos-metodológicos de referência, não há mais o que se apreciar em termos de uma 
entidade avaliadora do que se fez. A fiscalização, antes atestada pela modalidade pragmática, é suavizada, relaxada.

As modalizações sempre são agenciadas para corroborar com a qualificação do objeto do discurso "ser professor". Os estagiários narram a mudança de status do que antes era apenas uma nomeação "vocês agora são professores" para a assunção gradativa do papel professor que termina na consolidação do mesmo. O "nos" revela já a condição de membro e a tomada de posicionamento do ser professor e os efeitos disso para as atribuições de sala de aula.

\section{Considerações finais}

O trabalho de pesquisa interinstitucional em curso, do qual trouxemos para este trabalho dados preliminares, atesta a importância da análise da discursivização sobre o trabalho do professor e as representações do agir e da identidade profissional indiciadas via textualização pelos estagiários em seus relatórios. Aponta também para o quanto a enunciação desses sujeitos nos informa sobre o movimento pendular de construção de argumentação a partir da ancoragem de representações em discursos do senso comum e acadêmico-científicos de referência na formação inicial do professor (quadro teóricometodológico). E sobretudo o impacto da mobilização e construção de objetos de discurso como professor, interação didática, ensino-aprendizagem de língua e identidade profissional a partir da referência, objetivação e ancoragem a um ou outro discurso.

Trata-se, sobretudo, de "tocar", de perceber nos relatórios de estágio aquilo que subjaz, aquilo que orienta o dizer, aquilo que "escapa", aquilo que concorre para as representações identitárias desses sujeitos. Para, assim, flagrar nesses dizeres efeitos das nossas propostas de produção textual acadêmica.

A análise dos excertos realizada indicia que: i)há a necessidade de traçar estratégias metodológicas mais contundentes para o trabalho com o gênero relatório de estágio; ii) a textualização das vivências de observação e regência são tão centrais para a formação do sujeito, assim como a mostra delas para seu professor formador; iii) as identidades são (re)construídas no e pelo relatório de estágio; iv) há que se buscar entender sempre melhor as condições de produção de sentido implicadas na atividade de textualização, desde a demanda, sua realização e até a sua avaliação e, por fim, v)há finalidades discursivas 
implicadas na instância de regulação da ação.

Surpreendemo-nos com os usos e efeitos de usos das modalizações recorrentes nas produções de estagiários de duas universidades geograficamente afastadas. Se, como sabemos, não incitamos a avaliação negativa da prática do outro (o professor em exercício) nas coordenadas de demanda das atividades e se tampouco incentivamos uma suavização da análise da própria prática dos estagiários, isso não apenas ocorre, mas recorre porque há alinhamentos e realinhamentos identitários em curso alimentados por representações sociais estabilizadas de um agir. Ou seja, ao analisarmos os relatórios de estágios estamos, sim, analisando sob certo ângulo a identidade profissional desses sujeitos em construção.

Experimentar e praticar a análise de dizeres de licenciandos em relatórios de estágio de observação e regência têm requerido de nós necessariamente uma atitude política que visa uma intervenção no universo da nossa própria formação, como formadoras de professores, a partir de um alargamento da compreensão, via sistematização e pesquisa, de gêneros acadêmicos que materializam diferentes estágios do letramento acadêmico e profissional de sujeitos na formação inicial do professor. Ao assumirmos institucionalmente o projeto de formação de trabalharmos com disciplinas do núcleo de metodologias e práticas de ensino, influenciamos e somos influenciadas por certas escolhas de pesquisa. Daí o duplo movimento: fazer pesquisa a partir de necessidades de didatização e didatizar a partir de pesquisas (ZANDWAIS, 2012).

\section{Referências}

BRONCKART, Jean-Paul. Atividade de linguagem, textos e discursos: por um interacionismo sociodiscursivo. São Paulo: Educ, 1999.

BRONCKART, Jean-Paul. Atividade de linguagem, discurso e desenvolvimento humano. Campinas: Mercado de Letras, 2006.

BRONCKART, J. P. Gêneros de textos, tipos de discurso e sequências. Por uma renovação do ensino da produção escrita. Letras, Santa Maria, v. 20, n. 40, p.163-176, jan./jun. 2010.

BRONCKART, J-P. Atividade de linguagem, discurso e desenvolvimento humano. Org. Anna Rachel Machado e Maria de Lourdes Meirelles Matencio. Trad. Anna Rachel Machado, Maria de Lourdes Meirelles Matencio et. al. Campinas: Mercado de Letras, 2006. 
FAÏTA, Daniel. Gêneros de discurso, gêneros de atividade, análise da atividade do professor. In: O Ensino como Trabalho: uma abordagem discursiva. RACHEL, Anna Machado (Org). Londrina: Eduel, 2004 .

GUIMARÃES, Ana Maria de Mattos; MACHADO, Ana Raquel. Apresentação. In: GUIMARÃES, A.; MACHADO, A.; COUTINHO, A. (orgs.). O interacionismo sociodiscursivo: questões epistemológicas e metodológicas. Campinas: Mercado de Letras, 2007. p.9-16.

HOLLAND, Dorothy; LACHICOTTE, William Jr.; SKINNER, Debra; CAIN, Carole. Identity and Agency in Cultural Worlds. London: Harvard University Press, 1998.

KLEIMAN, Ângela; MATENCIO, Maria de Lourdes (orgs). Letramento e formação do professor. Campinas, SP: Mercado de Letras, 2005.

KLEIMAN, A.B. Letramento e suas implicações para o ensino de língua materna. Signo, v. 32, n. 53, p. 1-25, 2007.

LEURQUIN, Eulália Vera Lúcia Fraga e BOTELHO. Nível de letramento de professores de língua portuguesa em formação e situação de interação através do gênero acadêmico relatório de estágio. In: LEURQUIN; BEZERRA; SOARES (orgs). Gênero Ensino e Formação de professores. São Paulo: Mercado de Letras, 2011.

LEURQUIN, Eulália Vera Lúcia Fraga; PEIXOTO, Camila Maria Marques. A construção de um agir reflexivo doprofessor no espaço de formação docente. SCRIPTA, Belo Horizonte, v. 15, n. 28 , p. 83-102, $1^{\circ}$ sem. 2011, p. 83-102.

LEURQUIN, Eulália V. L. O relatório de observação de aulas como um viés de acesso ao ensino/aprendizagem de língua materna. In: MATTES, M.; THEOBALD, P. (orgs.). Ensino de línguas: questões práticas e teóricas. Fortaleza: UFC, 2008. p. 57-79.

LOPES, Maria Angela. Relatórios de estágio: opacidade e vaguidão na análise do agir do professor. In: GUIMARÃES, A.; MACHADO, A.; COUTINHO, A. (orgs.). O interacionismo sociodiscursivo: questões epistemológicas e metodológicas. Campinas: Mercado de Letras, 2007. p. 221-236.

MACHADO, A. R. (Org.). O ensino como trabalho: uma abordagem discursiva. Londrina, PR: Eduel, 2004.

MATENCIO, Maria de Lourdes Meirelles. Gêneros na formação do professor: construção de saberes e de representações em atividades interacionais. Estudos Linguísticos/Linguistic Studies, 3. Edições Colibri/CLUNL, Lisboa, 2009, p.17-28.

NEVES, Janete dos Santos Bessa. Estudo semântico-enunciativo da modalidade em artigos de opinião. Tese (Doutorado em Letras)- Pontifícia Universidade Católica do Rio de Janeiro. Programa de Pós-Graduação em Letras. Rio de Janeiro, 2006. 
SILVA, Wagner Rodrigues. Escrita do gênero relatório de estágio supervisionado na formação inicial do professor brasileiro. RBLA, Belo Horizonte, vol.13, n.1, , 2013,pp. 171-195.

SILVA, W. R.; MELO, L. C. de. Relatórios de estágio supervisionado como gênero discursivo mediador da formação do professor de língua materna. Trabalhos em Linguística Aplicada, Campinas, v. 47, n. 1, 2008,p. 131-149.

SCHNEUWLY, Bernard. Gêneros e tipos de discursivo; considerações psicológicas e ontogenéticas. In: SCHNEUWLY. B; DOLZ, J. Gêneros orais e escritos na escola. Trad. de Roxane Rojo e Glaís Sales Cordeiro. Campinas: Mercado de Letras, 2004.

ZANDWAIS, A. Demandas da pesquisa e diálogos entre teoria e prática. In: LEFFA, V.; ERNST, A. (Org). Linguagens: metodologias de ensino e pesquisa. Pelotas: Educat, 2012, p.1326.

\footnotetext{
' Pollyanne Bicalho RIBEIRO - Doutora em Linguística e Língua Portuguesa pela PUCMinas. Professora Adjunta do Departamento de Letras Vernáculas e Professora do Mestrado Profissionalizante em Letras (PROFLETRAS) da mesma universidade. pollyanne_br@yahoo.com.br
}

\footnotetext{
ii Fernanda de Castro MODL - Doutora em Linguística e Língua Portuguesa pela PUCMinas. Professora Adjunta do Departamento Estudos Linguísticos e Literários (DELL) da Área de Metodologia e Práticas de Ensino (AMPE) e Professora do Mestrado em Letras: Cultura, Educação e Linguagens (PPGCEL) da mesma Universidade. fernanda.modl.vesb@gmail.com
} 